\title{
PENGARUH PENAMBAHAN KAPUR TERHADAP KUAT TEKAN BEBAS PADA TANAH LEMPUNG PADA AIMAS KAUPATEN SORONG
}

\author{
Melki \\ Program Studi Teknik Sipil Universitas Muhammadiyah Sorong \\ Jalan Pendidikan No 27 Kota Sorong, Propinsi Papua Barat \\ Email: melkymelky65@gmail.com
}

\begin{abstract}
ABSTRAK
Tanah merupakan pijakan terakhir untuk menerima pembebanan yang berkaitan dengan pembangunan jalan, jembatan, landasan, gedung, dan lain-lain. Tanah yang akan di jadikan tanah dasar untuk sebuah proyek pembangunan harus di perhitungkan terlebih dahulu sebelum para pelaku pembangunan akan melakukan pembangunan di atasnya, agar hasil pekerjaan dapat dimanfaatkan secara optimum oleh penggunanya. Tanah yang kurang baik daya dukungnya sebaiknya harus di perhitungkan pada saat pembangunan suatu bangunan diatasnya, solusinya adalah perlu adanya stabilisasi tanah. Pada penelitian ini, stabilisasi tanah dilakukan dengan pencampuran tanah dengan kapur sebagai zat aditif pengikat tanah. Kapur dipilih karena sifat nya yang cukup baik dalam mengikat partikel-partikel tanah sehingga dapat meningkatkan kuat tekan bebas tanah. Uji kuat tekan bebas (Unconfined Compression Test) adalah salah satu uji tanah yang umum dilakukan pada tanah lempung. Dari hasil uji ini akan diketahui parameter tegangan runtuh (qu), dan $\mathrm{Cu}$ merupakan nilai kohesi sekaligus nilai tegangan geser tanah tersebut. Dari latar belakang tersebut penulis menganggap perlu melakukan penelitian, dengan judul "PENGARUH PENAMBAHAN KAPUR TERHADAP KUAT TEKAN BEBAS PADA TANAH LEMPUNG STUDI KASUS JALAN INTIMPURA DISTRIK AIMAS KAUPATEN SORONG". Tujuan penelitian ini yaitu untuk menganalisis karakteristik tanah asli pada Jalan Intimpura Distrik Aimas Kabupaten Sorong; menganalisis karakteristik tanah lempung yang telah di stabilisasi dengan menggunakan bahan additive kapur yang variasi campurannya berbeda-beda; dan mengidentifikasi seberapa besar pengaruh penambahan kapur pada tanah lempung terhadap kuat tekan bebas. Metode penelitian yang digunakan adalah dengan pengujian tanah asli serta menambahkan bahan tambah yang distabilisasi.
\end{abstract}

Kata Kunci : stabilisasi tanah; kapur; kuat tekan bebas

\section{PENDAHULUAN}

Tanah merupakan pijakan terakhir untuk menerima pembebanan yang berkaitan dengan pembangunan jalan, jembatan, landasan, gedung, dan lain - lain. Tanah yang akan di jadikan tanah dasar untuk sebuah proyek pembangunan harus di perhitungkan terlebih dahulu sebelum para pelaku pembangunan akan melakukan pembangunan di atasnya, agar hasil pekerjaan dapat dimanfaatkan secara optimum oleh penggunanya. Tanah yang kurang baik daya dukungnya seaiknya harus di perhitungkan pada saat pembangunan suatu bangunan diatasnya, solusinya adalah perlu adanya stabilisasi tanah. Tanah lempung mempunyai sifat yang kurang baik yaitu mempunyai kuat tekan rendah, kuat geser rendah setelah dikenai beban, kapilaritas tinggi, permeabilitas rendah dan kerapatan relatif rendah. Sifat- sifat yang buruk pada tanah dapat mengganggu suatu konstruksi sehingga konstruksi dapat mengalami kerusakan struktur. Karena kelemahan- kelemahan tersebut, tanah lempung jelas memerlukan penanganan sebelum di atas tanah tersebut didirikan suatu konstruksi. Pada penelitian ini, stabilisasi tanah dilakukan dengan pencampuran tanah dengan kapur sebagai zat aditif pengikat tanah. Kapur dipilih karena sifat nya yang cukup baik dalam mengikat partikel - partikel tanah sehingga dapat meningkatkan kuat tekan bebas tanah. Kapur memiliki sifat sifat yang kurang lebih sama seperti semen dan juga dalam segi harga, kapur lebih murah dibandingkan dengan 
semen sehingga akan lebih efisien dalam biaya stabilisasi tanah. Dalam pekerjaan tanah, kuat tekan bebas adalah salah satu faktor yang menentukan dalam keseluruhan pekerjaan proyek konstruksi. Uji kuat tekan bebas (Unconfined Compression Test) adalah salah satu uji tanah yang umum dilakukan pada tanah lempung. Dari hasil uji ini akan diketahui parameter tegangan runtuh (qu), dan $\mathrm{Cu}$ merupakan nilai kohesi sekaligus nilai tegangan geser tanah tersebut. Dari latar belakang tersebut penulis menganggap perlu melakukan penelitian, dengan judul "PENGARUH PENAMBAHAN KAPUR TERHADAP KUAT TEKAN BEBAS PADA TANAH LEMPUNG STUDI KASUS JALAN INTIMPURA DISRIK AIMAS KAUPATEN SORONG”. Tujuan penelitian ini yaitu untuk menganalisis karakteristik tanah asli pada Jalan Intimpura Distrik Aimas Kabupaten Sorong; menganalisis karakteristik tanah lempung yang telah di stabilisasi dengan menggunakan bahan additive kapur yang variasi campurannya berbeda-beda; dan mengidentifikasi seberapa besar pengaruh penambahan kapur pada tanah lempung terhadap kuat tekan bebas.

\section{STATE OF THE ART}

Adapun penelitian terdahulu yang terkait dengan penelitian ini adalah sebagai berikut :

1. Menurut oleh Putra Andrean A. (2016) yang meneliti tentang: "Pengaruh Variasi Waktu Pemeraman Terhadap Nilai Kuat Tekan Bebas Pada Tanah Lempung Dan Lanau yang di Stabilisasi Menggunakan Kapur Pada Kondisi Rendaman" berikut hasil penelitian tersebut;

1. Jenis tanah yang digunakan sebagai sampel penelitian ini ada 2 jenis yaitu, tanah lempung yang berasal dari daerah Rawa Sragi, Desa Belimbing Sari Kecamatan Jabung, Kabupaten Lampung Timur dan tanah lanau yang berasal dari Desa Yosomulyo, Kecamatan Metro Timur. Berdasarkan klasifikasi tanah menurut USCS (Uniffied Soil Clasification System), tanah lempung termasuk ke dalam kelompok OH yaitu lempung organik dengan plastisitas sedang sampai dengan tinggi, sedangkan tanah lanau termasuk ke dalam kelompok ML yaitu tanah lanau anorganik dengan plastisitas rendah.

2. Dari hasil uji pemadatan modified proctor, penambahan campuran kapur pada tanah lempung dan tanah lanau terbukti meningkatkan nilai berat volume maksimum $(\gamma \mathrm{d})$ secara continue dari kadar kapur 5\%, $10 \%$, sampai $15 \%$ dan durasi pemeraman dari 7 hari, 14 hari, sampai 28 hari.

3. Uji kuat tekan bebas dilakukan pada tanah lempung dan lanau yang diberi tambahan kapur masingmasing $5 \%, 10 \%$, dan 15\%, kemudian diperam dengan lama waktu variasi pemeraman masing-masing 7 hari, 14 hari, dan 28 hari. Setelah dilakukan pemeraman, sampel tanah direndam selama 4 hari (soaked) sebelum diuji.

4. Dari hasil pengujian kuat tekan bebas yang dilakukan di laboratorium dapat dilihat kenaikan dan penurunan nilai kuat tekan bebas pada setiap penambahan campuran kapur, akan tetapi kecenderungannya mengalami kenaikan. Pada tanah lempung, nilai kuat tekan bebasnya (qu) cenderung mengalami kenaikan dari kadar kapur 5\%, 10\%, sampai 15\%. Pada sampel tanah lempung 5\% kapur, pemeraman 14 hari didapatkan nilai qu yang paling besar dibandingkan dengan pemeraman 7 hari dan 28 hari. Kemudian pada tanah lempung dengan kapur $10 \%$ dan $` 15 \%$, semakin lama variasi waktu pemeramannya, hasil kuat tekan yang semakin baik. Sampel tanah lempung $+15 \%$ kapur dengan lama waktu pemeraman 28 hari didapat nilai kuat tekan bebas (qu) paling besar (optimum) dari sampel tanah lempung lainnya yaitu sebesar $0,3636 \mathrm{~kg} / \mathrm{cm} 2$.

5. Dari hasil uji kuat tekan bebas tanah lanau, sampel dengan kapur 5\% tidak menunjukkan peningkatan nilai kuat tekan bebas (qu) yang signifikan di setiap variasi lama waktu pemeramannya. Namun pada sampel dengan kapur $10 \%$ dan 15\%, didapatkan kenaikan nilai (qu) yang cukup signifikan. Sampel yang dicampur 10\% kapur sudah menunjukkan nilai qu yang baik mulai dari pemeraman 7 hari dan terus meningkat pada pemeraman 14 hari dan 28 hari. Pada sampel dengan 15\% kapur, baru terlihat peningkatan setelah pemeraman 14 dan 28 hari. Sampel tanah lanau dengan 15\% kapur dengan pemeraman 28 hari mendapatkan nilai kuat tekan bebas (qu) paling besar.

6. Dari pengujian kuat tekan bebas tanah lempung dan lanau, dapat disimpulkan bahwa lama waktu pemeraman berpengaruh terhadap kuat tekan bebas tanah campuan kapur, semakin lama waktu pemeraman, nilai kuat tekan bebas (qu) semakin mengalami kenaikan. Hal ini disebabkan proses sementasi yang terjadi antara kapur dan tanah perlu waktu yang cukup lama. Kapur menunjukkan 
pengaruh yang lebih baik pada tanah lempung dibandingkan dengan tanah lanau, walaupun perbedaannya tidak terlalu signifikan.

2. Menurut Muhamad Fadhilah Derajat (2019) yang meneliti tentang "Pengaruh Pemeraman Terhadap Stabilisasi Tanah Lempung Dengan Kapur Tohor Sebagai Lapisan Tanah Dasar Jalan Mariat Pantai” menyebutkan hasil penelitiannya yaitu;

1. Untuk pengujian sifat-sifat fisis tanah asli mariat pantai didapat nilai kadar air sebesar $19 \%$, berat jenis sebesar 2,49 gr/cm3, Lolos saringan 200 sebesar 78,04\%, batas cair sebesar 54,99\%, batas plastis sebesar 28,09\%, dan indeks plastisitas sebesar 26,90\%. Selain itu, tanah di daerah ini juga termasuk dalam jenis tanah lempung A-7-6 yaitu berlempung sedang sampai buruk menurut AASHTO dan menurut USCS termasuk dalam kategori $\mathrm{CH}$ yaitu tanah lempung anorganik dengan plastisitas tinggi.

2. Sifat-sifat fisis tanah di Daerah Mariat Pantai mengalami perubahan setelah dilakukan stabilisasi tanah dengan kapur tohor yaitu terlihat dari batas cair $6 \%=49,24 \%, 8 \%=48,11 \%, 10 \%=47,39 \%, 12 \%=44,29 \%$, $15 \%=44,68 \%$ dengan rata-rata pengaruh penurunan sebesar $2,68 \%$, batas plastis $6 \%=23,67,8 \%=23,45 \%$, $10 \%=22,98 \%, 12 \%=21,58 \%, 15 \%=20,34 \%$ dengan rata-rata pengaruh penurunan sebesar $1,55 \%$, Indeks plastisitas $6 \%=25,57 \%, 8 \%=24,66 \%, 10 \%=24,41 \%, 12 \%=22,71 \%, 15 \%=24,34 \%$ dengan rata-rata pengaruh penurunan sebesar $1,05 \%$. Sedangkan Berat jenis yang mengalami peningkatan dari tanah asli yaitu $6 \%=2,62 \mathrm{~g} / \mathrm{cm}^{3} 8 \%=2,67 \mathrm{~g} / \mathrm{cm}^{3}, 10 \%=2,73 \mathrm{~g} / \mathrm{cm}^{3}, 12 \%=2,64 \mathrm{~g} / \mathrm{cm}^{3}, 15 \%=2,61 \mathrm{~g} / \mathrm{cm}^{3}$ dengan ratarata pengaruh kenaikan sebesar $0,08 \mathrm{~g} / \mathrm{cm}^{3}$.

3. Dari hasil pengujian CBR didapatkan nilai CBR tanah asli yaitu 53,72\%. Setelah dilakukan pencampuran kapur tohor menggunakan waktu pemeraman, CBR mengalami peningkatan dengan nilai CBR tertinggi pada persentase kadar kapur $8 \%$ yaitu sebesar $63,39 \%$.

4. Berbeda dengan hasil peneliti sebelumnya yang mendapat nilai CBR dengan metode tanpa pemeraman dengan peningkatan nilai CBR tertinggi pada kadar kapur $6 \%$ dengan nilai 48,41\% dari nilai CBR tanah asli sebesar $46,48 \%$.

\section{METODE PENELITIAN}

Metodologi yang digunakan dalam penyusunan skripsi ini ialah yaitu dengan metode eksperimen yang dilakukan dengan mengadakan kegiatan pengujian untuk mendapatkan data. Data tersebut kemudian diolah untuk mendapatkan perbandingan dengan syarat-syarat yang ada, kemudian menganalisa data tersebut berdasarkan teori yang berkaitan dengan kondisi dari sampel tanah tersebut.

Semua metode penulisan dan analisa dalam artikel ilmiah ini merujuk pada panduan penulisan tugas akhir Fakultas Teknik Universitas Muhammadiyah Sorong tahun 2014 (Pristianto, Amri, \& Rusdi, 2014).

\section{REFERENSI}

Putra Andrean A. (2016). Pengaruh Variasi Waktu Pemeraman Terhadap Nilai Kuat Tekan Bebas Pada Tanah Lempung Dan Lanau yang di Stabilisasi Menggunakan Kapur Pada Kondisi Rendaman

Muhamad Fadillah Derajat (2019). Pengaruh Pemeraman Terhadap Stabilisasi Tanah Lempung Dengan Kapur Tohor Sebagai Lapisan Tanah Dasar Jalan Mariat Pantai

Hardiyatmo. H. C, (2002). Mekanika Tanah 1 Edisi ke-tiga, Universitas Gadjah Mada, Yogyakarta.

Hardiyatmo. H. C, (2010). Stabilitas Tanah Untuk Perkerasan Jalan, Universitas Gadjah Mada, Yogyakarta. 
Pristianto, H., Amri, I., \& Rusdi, A. (2014, May 9). Pedoman Penulisan Tugas Akhir Fakultas Teknik Universitas Muhammadiyah Sorong 2014. http://doi.org/10.17605/OSF.IO/4VTJM.

SNI Revisi Dari 03 - 1964 - 1990 Ke 1964 - 2008 Metode Pengujian Berat Jenis Tanah.

SNI Revisi Dari 03 - 1965 - 1990Ke 1965 - 2008 Metode pengujian Kadar Air.

SNI Revisi Dari 03 - 1966 - 1990 Ke 1966 - 2008 Metode Pengujian Batas plastis.

SNI Revisi Dari 03 - 1967 - 1990 Ke 1967 - 2008 Metode Pengujian Batas Cair Dengan Alat Cassagrande.

SNI Revisi Dari 03 - 3423 - 1994 Ke 3423 - 2008 Metode pengujian Analisis Ukuran Butir Tanah Dengan Alat Hidrometer. 